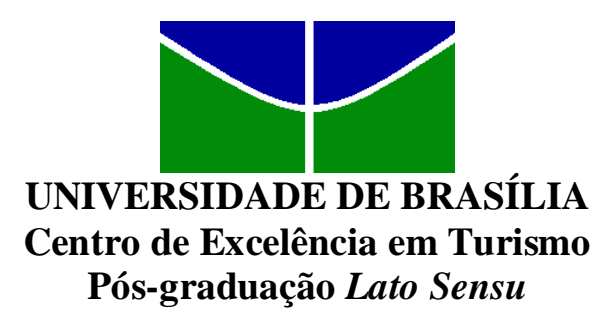

Curso de Especialização em Qualidade em Alimentos

\title{
ANÁLISE DE ROTULAGEM DE CARNES IN NATURA EMBALADAS A VÁCUO, EM BRASÍLIA-DF
}

\author{
Mateus Dias da Costa Fernandes \\ 2009/53091
}

Brasília - 2009 


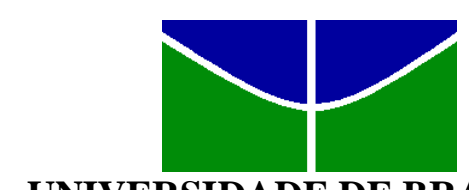

UNIVERSIDADE DE BRASÍLIA

Centro de Excelência em Turismo

Pós-graduação Lato Sensu

Curso de Especialização em Qualidade em Alimentos

\title{
ANÁLISE DE ROTULAGEM DE CARNES IN NATURA EMBALADAS A VÁCUO, EM BRASÍLIA-DF
}

\author{
Mateus Dias da Costa Fernandes \\ 2009/53091
}

Monografia apresentada ao Centro de Excelência em Turismo - CET, da Universidade de Brasília UnB, como requisito à obtenção do título de Especialista.

Orientadora: Prof ${ }^{a}$. MSc. Karla Lisboa Ramos

Brasília, 10 de agosto de 2009 


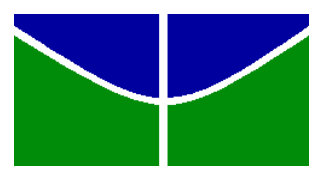

UNIVERSIDADE DE BRASÍLIA

Centro de Excelência em Turismo

Pós-graduação Lato Sensu

Curso de Especialização em Qualidade em Alimentos

\section{Mateus Dias da Costa Fernandes}

\section{Aprovado por:}

Professor orientador: Msc. Karla Lisboa Ramos

Professor: Msc. Lucienne Cardoso

Professor: Msc. Manoel Silva Neto

Brasília, 10 de agosto de 2009. 


\section{DEDICATÓRIA}

Dedico este trabalho à minha mãe, que me mostrou o mundo dos alimentos; à minha irmã, que sempre me serviu de inspiração profissional e à minha futura esposa, por me amar e sempre estimular meu progresso. 


\section{AGRADECIMENTOS}

Agradeço a meus professores, por aumentarem meu conhecimento e satisfação pelo estudo; a meus colegas de curso, pela amizade e companheirismo e a todos aqueles que, direta ou indiretamente, contribuíram colaboraram para a conclusão deste trabalho. 


\section{EPÍGRAFE}

Bebida é água.

Comida é pasto.

Você tem sede de quê?

Você tem fome de quê?

(Arnaldo Antunes, Marcelo Fromer e Sérgio Brito) 


\section{RESUMO}

A validação das rotulagens de empresas produtoras de carnes in natura embaladas a vácuo é realizada por fiscais federais agropecuários do Ministério da Agricultura, Pecuária e Abastecimento. No entanto, muitas empresas já encaminham o pedido da impressão de um grande número de rótulos a editoras, não respeitando as modificações recomendadas pelos fiscais. Com isso, em alguns casos, erros graves são encontrados nas rotulagens de produtos registrados e liberados para o mercado. Diante disso, o consumidor pode encontrar informações em desacordo com as normas estabelecidas por órgãos regulamentadores, podendo consumir produtos de empresas em desacordo com a legislação, ou ainda, produtos desaconselháveis à saúde do consumidor. O presente estudo objetivou identificar as principais não-conformidades encontradas nos rótulos de peças cárneas in natura, assim como, especificamente, analisou os rótulos dos alimentos em questão, determinou a freqüência de não-conformidades e identificou as não-conformidades mais freqüentes, encontrando várias não-conformidades relacionadas ao carimbo da inspeção federal, à marca do produto e à composição do produto. Entretanto, o item crítico, em relação à saúde do consumidor, foi a conservação do produto, cujas não-conformidades podem acarretar sérios problemas de saúde. Palavras-chave: análise, rotulagem, carnes. 


\begin{abstract}
The validation of the labels of producing companies of meats in natura packed by vacuum is carried through by farming federal inspectors of the Ministry of Agriculture, Cattle and Supplying. However, many companies already direct the order of the impression of a great number of labels for publishing companies, not respecting the modifications recommended by the inspectors. With this, in some cases, serious errors are found in the labels of registered and set free products for the market. Ahead of this, the consumer can find information in disagreement with the norms established by legal agencies or consume products of companies in disagreement with the legislation, or still, consume products inadivisable to the health of the consumer. The present study objectified to identify not-conformities found in the labels of meet pieces, as well as, specifically, analyzed the labels of foods in question, determined the frequency of not-conformities and identified not-conformities most frequent, finding some not-conformities related to the stamp of the federal inspection, to the mark of the product and the composition of the product. However, the critical item, relationed to the health of the consumer, was the conservation of the product, whose not-conformity can cause serious problems for the health.
\end{abstract}

Key words: analysis, labeling, meat. 


\section{SUMÁRIO}

INTRODUÇÃO.................................................................... 10

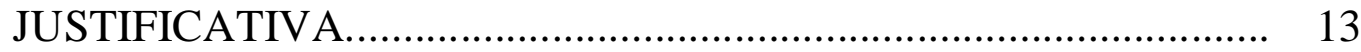

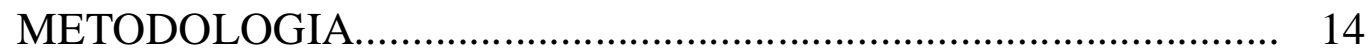

CAPÍTULO I - A CADEIA PRODUTIVA..................................... 15

CAPÍTULO II - LEGISLAÇÃO...................................................... 17

CAPÍTULO III - QUALIDADE.................................................... 23

RESULTADOS E DISCUSSÃO_.................................................... 25

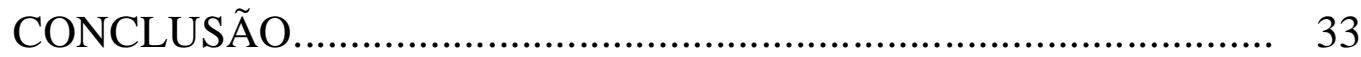

REFERÊNCIAS BIBLIOGRÁFICAS....................................... 34

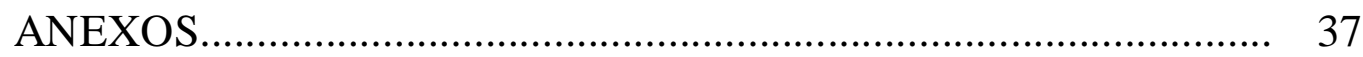




\section{INTRODUÇÃO}

Nos últimos anos, com o crescimento das exportações brasileiras e as possibilidades de inserção em mercados usualmente não atendidos pelo Brasil, mostrou-se apropriada a realização de estudos mais amplos e o levantamento das informações disponíveis sobre a cadeia de carne bovina no Brasil e sua relação com o mercado mundial. Os elos dessa cadeia ainda têm importantes problemas de coordenação. Admite-se que isso seja decorrência da cultura do produtor rural, dos limites na implantação da legislação sanitária, da capacidade de intervenção dos órgãos sanitários responsáveis, das diferenças tecnológicas, econômicas e sociais entre as diferentes regiões do País e, sobretudo, dos diferentes níveis de profissionalização do setor. (BRASIL, 2007)

A partir da década de 1980, o público teve sua conscientização aumentada a respeito da relação entre dieta e saúde. A maioria das pessoas já considera que a dieta é um fator determinante da saúde, atualmente. (CELESTE, 2001)

Não obstante, há diversas informações em rótulos alimentícios que podem ser enganosas, considerando-se a constante utilização de palavras ambíguas, confusas e termos vagos, já que uma mesma expressão pode apresentar significados totalmente diferentes de acordo com o fabricante. (DIBB, 1997)

Segundo a American Dietetic Association (1990), essa prática pode prejudicar o consumidor economicamente, no instante em que dinheiro é gasto em um produto divergente do anunciado. Além disso, a prática de propaganda enganosa em rótulos de alimentos prejudica campanhas de educação alimentar, levando à crença de que alguns produtos possuem propriedades medicinais, o que leva a um atraso na procura por cuidado médico adequado. (CELESTE, 2001)

De acordo com a World Health Organization (1986), medidas legislativas, como as regulamentações sobre rotulagem alimentar, são consideradas importantes atividades para a promoção de saúde. O uso dessas é justificado como modo de auxiliar as pessoas a otimizar sua alimentação, objetivando a garantia aos consumidores do acesso à informação útil e confiável, encorajando a comercialização de produtos mais saudáveis. (YETLEY ET RADER, 1996) 
Existem duas principais formas de transmissão de informação nutricional em rotulagem. A primeira é a propaganda nutricional, como a expressão "rico em fibras", que aparece geralmente no painel principal da embalagem. O outro modo é a descrição nutricional, que normalmente está no painel posterior da embalagem e apresenta as quantidades de calorias, gorduras, carboidratos, dentre outros nutrientes. (CELESTE, 2001)

Previamente à publicação da legislação brasileira referente a alimentos, discutiam-se os problemas de alimentação e nutrição no âmbito de congressos e reuniões de comissões governamentais, resultando, na maior parte das vezes, na publicação de material didático e informativo. (FERREIRA ET LANFER-MARQUEZ, 2007)

A publicação das primeiras leis ocorreu no final da década de 1960, destacando-se, em 1969, o Decreto-Lei no 986. Este, embora apresentasse definições e procedimentos posteriormente incorporados em outras publicações, continua vigente, devido à sua abrangência. (FERREIRA ET LANFER-MARQUEZ, 2007) Esse Decreto-Lei estabelece definições sobre alimentos, procedimentos para o registro e controle, rotulagem, critérios de fiscalização e detecção de alterações. (BRASIL, 1969)

Na década de 1940, foi criado o Departamento Nacional da Produção Animal, órgão integrante do Ministério da Agricultura que, mesmo não possuindo um regulamento específico, encarregava-se da fiscalização de produtos de origem animal, incluindo sua rotulagem, aprovando e registrando rótulos e carimbos oficiais utilizados na identificação de produtos e subprodutos preparados nos estabelecimentos sob inspeção federal. Também era responsável por realizar concessão e cassação de registros de estabelecimentos industriais sujeitos à fiscalização sanitária e de rótulos usados nos estabelecimentos em questão. (BRASIL, 1948)

Já a partir da década de 1950, foi elaborado pelo Brasil o Regulamento da Inspeção Industrial e Sanitária de Produtos de Origem Animal, RIISPOA, que estabelece em seu artigo número 794, a obrigatoriedade de todos os produtos de origem animal enviados ao comércio estarem identificados por meio de rótulos registrados, aplicados sobre as matérias-primas, produtos, vasilhames ou continentes, sejam os mesmos diretamente destinados ao consumo público, ou destinados a outros estabelecimentos beneficiadores. (BRASIL, 1952) O Regulamento em 
questão também expressa claramente, em seu artigo número 801, ser proibida qualquer denominação, declaração, palavra, desenho ou inscrição que transmita falsa impressão, forneça indicação errônea de origem e de qualidade dos produtos. (BRASIL, 1952)

Entretanto, em 2005, foi realizado um estudo em Brasília intitulado Consulta aos Rótulos de Alimentos e Bebidas por Freqüentadores de Supermercados em Brasília, Brasil. O estudo indicou que a maioria, apesar de considerar importante a presença da informação nutricional nos rótulos, essa motivação não era suficiente para que os mesmos fossem lidos, havendo ainda os que considerassem que ninguém lê os rótulos, além daqueles que lêem rótulos por necessidade, devido a um estado patológico específico relacionado à alimentação. (MONTEIRO ET AL, 2005)

Todos os consumidores entrevistados foram questionados sobre os motivos ou razões que os levariam a não consultar os rótulos dos alimentos. Grande parte dos entrevistados alegou já conhecer as informações nutricionais dos produtos que normalmente compra. Outros ainda consideraram que essas informações nem sempre estão presentes. (MONTEIRO ET AL, 2005)

A comparação de produtos similares a partir de seus rótulos não foi muito citada pelos entrevistados como sendo uma motivação importante. No entanto, esse é uns dos objetivos de se estabelecer a rotulagem nutricional obrigatória. A comparação entre produtos similares propiciaria a oportunidade de escolher os alimentos mais saudáveis e mais adequados às necessidades nutricionais e físicas do consumidor, devendo ser este um fator a ser destacado no momento da elaboração de programas educativos sobre a rotulagem nutricional obrigatória. (MONTEIRO ET AL, 2005)

A rotulagem nutricional, como outras fontes de informação, faz parte de um processo educativo, não sendo um fim em si mesma, devendo ser elaborada para servir como instrumento para a educação em saúde. Para isso, é importante que o saber faça sentido na realidade do indivíduo, e que o conhecimento possa ser moldado de acordo com sua bagagem sociocultural, objetivando a melhoria das condições de vida e de saúde do mesmo. (MONTEIRO ET AL, 2005) 


\section{JUSTIFICATIVA}

Com a verificação, mesmo que tardia, dos erros freqüentemente encontrados em rotulagens de carnes in natura, é possível elaborar procedimentos criteriosos para uma análise mais efetiva dos processos de fabricação e rotulagem propriamente dita, garantindo ao consumidor informações fidedignas desse tipo de alimento.

O presente estudo justifica-se pela importância do fornecimento de informações adequadas ao consumidor que, na maior parte dos casos, não dispõe da base necessária para avaliação e interpretação de rótulos e, quando possui essa base, recebe informações equivocadas ou enganosas no produto.

Outra justificativa diz respeito ao número insuficiente de publicações sobre rotulagem, sendo as mesmas relativas apenas à rotulagem nutricional e não ao rótulo completo do produto, havendo também poucos estudos sobre rotulagem de produtos cárneos in natura, sendo a maioria sobre produtos processados.

Dessa forma, o presente estudo faz-se muito importante para o consumidor, em termos de conhecimento e até mesmo saúde, e às indústrias produtoras, em termos de garantia da qualidade e responsabilidade de produção. 


\section{METODOLOGIA}

Com o objetivo de identificar erros em diversas rotulagens de carnes in natura, realizou-se o estudo a partir de uma amostra censitária, em todo o Plano Piloto, em um estudo transversal, no período de Dezembro de 2008 a Janeiro de 2009, sendo analisados todos os rótulos de todos os produtos, carnes in natura embaladas industrialmente a vácuo, encontrados, totalizando 99 rótulos, em sete redes diferentes de estabelecimentos. Cada estabelecimento foi visitado duas vezes, garantindo a análise do maior número possível de rótulos.

Os produtos analisados pertenciam todos à classificação "Carne resfriada sem osso", havendo variação apenas quanto à nomenclatura dos cortes. A análise foi visual, no próprio estabelecimento, não sendo o produto manipulado, evitando assim possíveis contaminações e desvios na temperatura de armazenamento, assim como também foi evitado o gasto desnecessário com a compra das peças cárneas in natura. Os dados aferidos foram anotados em formulário específico (ANEXO 1).

A realização da coleta de dados foi realizada por observação direta. As variáveis avaliadas foram relativas às informações obrigatórias para rótulos de carnes in natura, além da apresentação do rótulo e das informações facultativas, seguindo-se uma escala nominal, de acordo com a presença ou ausência dessas informações. A análise estatística foi descritiva, avaliando-se a quantidade de não-conformidades e as não-conformidades mais frequentes. 


\section{CAPÍTULO I - A CADEIA PRODUTIVA}

Carnes para consumo humano devem ser preparadas a partir de animais saudáveis e dessangrados. Os animais que apresentam agentes infecciosos, tóxicos ou físicos, podendo ser nocivos à saúde humana, ou que possuam seus tecidos não saudáveis são impróprios para consumo humano. A adequação do alimento pode ser determinada pela avaliação abrangente, podendo incluir exames organolépticos, histológicos, microbiológicos, químicos ou toxicológicos. (BRASIL, 1950)

A tecnologia utilizada é de extrema importância no planejamento e gestão da pecuária de corte. Entre os aspectos tecnológicos relevantes de um empreendimento pecuário destacam-se a escolha das raças dos animais e os sistemas de manejo utilizados. (BRASIL, 2007)

Barros e Hausknecht (2005) afirmam que tecnologias capazes de elevar a produtividade na pecuária podem ser agrupadas naquelas que aumentam a produção de carne por animal (melhoramento genético, sanidade, mineralização, semiconfinamento e confinamento) ou que aumentam a produção por área (pastejo rotacionado, adubação, irrigação e integração lavourapecuária).

Há uma forte relação entre melhoramento genético e nutrição. A falta de alimento de qualidade reduz a vantagem do melhoramento e, sem esse, diminui-se à rentabilidade do alimento oferecido ao animal. Em relação ao aumento da produtividade por área, tecnologias como pastejo rotacionado, adubação, irrigação e integração lavoura-pecuária servem como opção, de forma alternada ou concomitantemente. A escolha depende da amplitude do sistema de produção e das exigências da região na qual a atividade está instalada. (BRASIL, 2007)

Parte da cadeia agroindustrial brasileira de carne bovina, excetuando-se aquela direcionada principalmente para a exportação, passa por um processo lento de reestruturação produtiva e de modernização tecnológica. Isso ocorre particularmente na produção para o mercado interno, tendo em vista as restrições de renda do consumidor e a ausência de pressão do mercado por padrões tecnológicos e produtos mais sofisticados. (BRASIL, 2007)

As tecnologias de abate e processamento de carnes são razoavelmente desenvolvidas e homogêneas em todo o mundo. Não existem diferenças tecnológicas importantes entre os 
grandes frigoríficos nacionais e seus competidores no mercado externo. Entretanto, o setor de abate e processamento pode empregar esforços para, a exemplo do ocorrido na indústria avícola, agregar valor às suas atividades através do desenvolvimento de produtos de conveniência, que não apresentem perda de qualidades organolépticas e nutricionais. (BRASIL, 2007)

A distribuição conta com uma realidade tecnológica mais avançada que aquela dos outros elos da cadeia agroindustrial da carne bovina. A evolução do mercado varejista, marcada pela concentração das grandes cadeias de supermercados em busca de economias de escala e escopo e pela busca de estratégias diferentes dessas por lojas independentes, tem impulsionado a modernização tecnológica desse setor. A tecnologia da informação, por exemplo, passou a ser amplamente utilizada, interligando e automatizando, em tempo real, as transações de compra e controle de estoques entre produtores/fornecedores e pontos de venda. (BRASIL, 2007)

Os demais avanços tecnológicos observados nos países desenvolvidos, principalmente voltados à área de embalagens e conservação (incluindo a cadeia do frio) são incorporados de forma rápida e direta, visto que as grandes empresas varejistas nacionais são, em grande parte, controladas por redes internacionais, principalmente dos Estados Unidos e França. (BRASIL, 2007) 


\section{CAPÍTULO II - LEGISLAÇÃO}

O Código de Proteção do Consumidor, Lei N 8078, de 11 de setembro de 1990, garante ao consumidor a informação adequada e clara sobre os diferentes produtos e serviços, com especificação correta de quantidade, características, composição, qualidade e preço. Também afirma que os produtos e serviços colocados no mercado de consumo não acarretarão riscos à saúde ou segurança dos consumidores. (BRASIL, 1990)

De acordo com a Lei $N^{\circ} 1283$, de 18 de Dezembro de 1950, é obrigatória a prévia fiscalização, sob o ponto de vista industrial e sanitário, de todos dos produtos de origem animal, comestíveis e não comestíveis, que sejam ou não adicionados de produtos vegetais, preparados, transformados, manipulados, recebidos, acondicionados, depositados e em trânsito. (BRASIL, 1950)

Estão sujeitos a essa fiscalização, entre outros, os animais destinados à matança, seus produtos e subprodutos, e matérias primas, sendo competentes para realizar essa tarefa o Ministério da Agricultura, as Secretarias ou Departamentos de Agricultura e os órgãos de saúde pública dos Estados, dos Territórios e do Distrito Federal. (AIELLO, 2001)

O Regulamento da Inspeção Industrial e Sanitária de Produtos de Origem Animal, em suas disposições preliminares, afirma que a inspeção desses produtos abrange, sob o ponto de vista industrial e sanitário, a inspeção "ante" e "post mortem" dos animais, o recebimento, manipulação, transformação, elaboração, preparo, conservação, acondicionamento, embalagem, depósito, rotulagem, trânsito e consumo de quaisquer produtos e subprodutos. (BRASIL, 1952)

Ainda de acordo com o Regulamento, entende-se por estabelecimento de produtos de origem animal qualquer instalação ou local nos quais são abatidos ou industrializados animais produtores de carnes, bem como onde são recebidos, manipulados, elaborados, transformados, preparados, conservados, armazenados, depositados, acondicionados, embalados e rotulados com finalidade industrial ou comercial, a carne e seus derivados. (BRASIL, 1952) 
A existência de legislação sobre embalagem e rotulagem de alimentos tem como objetivo proporcionar o emprego de uma linguagem padronizada entre os fabricantes de alimentos e embalagens, usuários e órgãos do governo, visando defender o consumidor. (BICK, 1986) (SANTOS ET CASTRO, 1998) (DE QUADROS, 2001)

Todos os produtos de origem animal entregues ao comércio devem ser identificados por meio de rótulos registrados, aplicados sobre as matérias-primas, produtos, vasilhames ou continentes, sejam diretamente destinados ao consumo público, ou se destinem a outros estabelecimentos beneficiadores. Os produtos de origem animal fracionados devem conservar a rotulagem sempre que possível ou manter identificação do estabelecimento de origem. (BRASIL, 1952)

Entende-se por rótulo toda inscrição, legenda, imagem ou toda matéria descritiva ou gráfica que esteja escrita, impressa, estampada, gravada, gravada em relevo ou litografada ou colada sobre a embalagem do alimento. (BRASIL, 2005)

A quantidade de produtos no mercado, com funções e embalagens similares exige do designer e do fabricante estratégias mercadológicas no intuito de vencer a competição acirrada com outras empresas. Com a finalidade de atrair e conquistar o consumidor, o produto deve atender uma demanda que envolve criatividade, beleza, funcionalidade, diferencial e, principalmente, preço acessível. (SCATOLIM, 2008)

A importância da rotulagem nutricional dos alimentos para a promoção da alimentação saudável é realçada na maioria dos estudos e pesquisas envolvendo a área da nutrição e sua relação com estratégias para a redução do risco de doenças crônicas. A crescente demanda da sociedade por informações confiáveis sobre os produtos exige esforço do governo e setor produtivo para implantação de uma efetiva rotulagem nutricional de alimentos. (BRASIL, 2005)

A rotulagem nutricional é um direito do consumidor. O rótulo deve conter informações sobre a composição nutricional dos alimentos em questão, considerando o tamanho da porção usualmente consumida e a composição desses alimentos quanto aos nutrientes, entre outros detalhes, visando à orientação e manutenção da saúde do consumidor. (SOUZA, 2005) 
A data de fabricação, de acordo com a natureza do continente ou envoltório, deve ser impressa, gravada, declarada por meio de carimbo ou outro processo, a juízo do DIPOA, detalhando dia, mês e ano, podendo este ser representado pelos dois últimos algarismos. (BRASIL, 1952)

Na composição de marcas é permitido o emprego de desenhos a elas alusivos, sendo proibido o uso de marcas, dizeres ou desenhos alusivos à Bandeira Nacional, símbolos ou quaisquer indicações referentes a atos, fatos e estabelecimentos da União, dos Estados, dos Territórios, dos Municípios e do Distrito Federal a menos que haja autorização expressa da autoridade competente, e também qualquer denominação, declaração, palavra, desenho ou inscrição que transmita falsa impressão, forneça indicação errônea de origem e de qualidade dos produtos, podendo essa proibição ser estendida, a juízo do DIPOA, às denominações impróprias. (BRASIL, 2005)

Os rótulos devem ser impressos, litografados, gravados ou pintados respeitando obrigatoriamente a ortografia oficial e o sistema legal de unidades e medidas. É permitido utilizar, em produtos destinados ao consumo em território nacional, rotulagem impressa, gravada, litografada ou pintada em língua estrangeira, com tradução em vernáculo, desde que sejam atendidos dispositivos constantes em tratados internacionais de mútuo comércio. (BRASIL, 2005)

O carimbo de Inspeção Federal representa a marca oficial utilizada exclusivamente em estabelecimento sujeitos à fiscalização do D.I.P.O.A., e constitui o sinal de garantia da inspeção do produto pela autoridade competente. O número de registro do estabelecimento, as iniciais "S.I.F." e, conforme o caso, as palavras "Inspecionado" ou "Reinspecionado", tendo na parte superior a palavra "Brasil", representam os elementos básicos do carimbo oficial da Inspeção Federal. (BRASIL, 2005)

Os carimbos utilizados para peças cárneas in natura possuidoras de rótulo em papel são os de modelo número 3, de forma circular, sendo de dois ou três centímetros de diâmetro para peças abaixo de um quilograma, e de quatro centímetros para peças acima de um quilograma. (BRASIL, 1952) (ANEXO 2) 
Os estabelecimentos comerciais podem apenas utilizar rótulos em matérias-primas e produtos de origem animal, quando devidamente aprovados e registrados pelo DIPOA. A aprovação e registro de rótulo devem ser requeridos pelo fabricante, que instruirá a petição. Os rótulos registrados devem apresentar impressa a declaração de seu registro no DIPOA, seguida do número respectivo. (BRASIL, 1975)

Nenhum rótulo, etiqueta ou selo pode ser aplicado escondendo ou encobrindo, total ou parcialmente, dizeres de rotulagem ou o carimbo da Inspeção Federal. Os carimbos oficiais em qualquer estabelecimento devem reproduzir fiel e exatamente os modelos determinados pelo RIISPOA, sob pena de responsabilidade da Inspeção Federal e da Inspetoria Regional sob jurisdição das quais esteja o estabelecimento faltoso. (BRASIL, 1975)

Desde 4 de Janeiro de 2000, todos os estabelecimentos relacionados adotaram o Regulamento Técnico para Rotulagem de Alimentos Embalados. O presente Regulamento Técnico é aplicado à rotulagem de todo produto de origem animal destinado ao comércio interestadual e internacional, qualquer que seja sua origem, embalado na ausência do cliente e pronto para oferta ao consumidor. (BRASIL, 1998)

De acordo com esse Regulamento, todos os produtos de origem animal embalados não devem ser descritos ou apresentar rótulo que: (BRASIL, 2005)

a) utilize vocábulos, sinais, denominações, símbolos, emblemas, ilustrações ou outras representações gráficas que possam tornar as informações falsas, incorretas, insuficientes, ou que possa induzir o consumidor a equívoco, erro, confusão ou engano, em relação à verdadeira natureza, composição, procedência, tipo, qualidade, quantidade, validade, rendimento ou forma de uso do produto de origem animal;

b) atribua efeitos ou propriedades que não possuam ou não possam ser demonstradas;

c) destaque a presença ou ausência de componentes que sejam intrínsecos ou próprios de produtos de origem animal de igual natureza, exceto nos casos previstos em regulamentos técnicos específicos;

d) ressalte, em certos tipos de produtos de origem animal processado, a presença de componentes que sejam adicionadas como ingredientes em todos os produtos de origem animal com tecnologia de fabricação semelhante;

e) ressalte qualidades que possam induzir a engano com relação a reais ou supostas propriedades terapêticas que alguns componentes ou ingredientes tenham ou possam ter 
quando consumidos em quantidades diferentes daquelas que se encontram no produto de origem animal ou quando consumidos sob forma farmacêutica;

f) indique que o produto de origem animal possui propriedades medicinais ou terapêuticas;

g) aconselhe seu consumo como estimulante, para melhorar a saúde, para prevenir doenças ou com ação curativa.

Nos rótulos das embalagens de produtos de origem animal que exijam condições especiais para sua conservação, deve ser incluída uma legenda com caracteres bem legíveis, indicando as precauções necessárias para manter suas características normais, devendo ser indicadas as temperaturas máxima e mínima para a conservação do produto de origem animal e o tempo que o fabricante, produtor ou fracionador garante sua durabilidade nessas condições. $\mathrm{O}$ mesmo dispositivo é aplicado para produto de origem animal que pode se alterar depois de abertas suas embalagens. (BRASIL, 2005)

Em particular, para os produtos de origem animal congelados, cujo prazo de validade varia segundo a temperatura de conservação, deve ser indicada esta característica. Nestes casos, pode ser indicado o prazo de validade para cada temperatura, em função dos critérios já mencionados, ou então o prazo de validade para cada temperatura, indicando o dia, o mês e o ano da fabricação. (BRASIL, 2005)

Quando necessário, o rótulo deve conter as instruções sobre o modo apropriado de uso, incluídos a reconstituição, o descongelamento ou o tratamento que deve ser dado pelo consumidor para o uso correto do produto. Estas instruções não devem ser ambíguas, nem dar margem a falsas interpretações, com a finalidade de garantir a utilização correta do produto de origem animal. (BRASIL, 2005)

Da rotulagem pode constar qualquer informação ou representação gráfica, assim como matéria escrita, impressa ou gravada, sempre que não haja contradição com os requisitos obrigatórios do Regulamento Técnico Para Rotulagem de Produto de Origem Animal Embalado, incluindo os referentes à declaração de propriedades e as informações enganosas. Essas denominações deverão ser de fácil compreensão e não deverão, de modo algum, levar o consumidor a equívocos, devendo cumprir com a totalidade dos parâmetros que caracteriza a qualidade do produto de origem animal. (BRASIL, 2005) 
A rotulagem dos produtos de origem animal deve ser feita exclusivamente nos estabelecimentos processadores, habilitados pela autoridade competente do país de origem, para elaboração ou fracionamento. (BRASIL, 2005)

No caso de peças maturadas, os cortes obtidos devem ser, obrigatoriamente, embalados a vácuo em películas de alta resistência mecânica, impermeáveis a gases e ao vapor d'água, sendo que estes devem ser identificados com, no mínimo, o carimbo de inspeção regulamentar. (BRASIL, 1988)

O Departamento Nacional de Inspeção de Produtos de Origem Animal (DIPOA), órgão central de direção superior do Ministério da Agricultura, criado pelo Decreto $n^{\circ} 73.474$, de 16 de Janeiro de 1974, é o responsável pelo planejamento, coordenação, supervisão, fiscalização e controle da inspeção, e classificação de produtos de origem animal in natura. (BRASIL, 1950)

Dessa maneira, cabe à Divisão de Inspeção de Carnes e Derivados, ligada ao DIPOA, examinar e apresentar parecer conclusivo sobre memoriais descritivos, invólucros e rótulos utilizados na identificação e embalagem dos produtos, para fins de registros e controle dos respectivos produtos e subprodutos de origem animal e seus derivados, na forma da legislação vigente. Ao diretor da DICAR cabe aprovar a utilização de rótulos e sua respectiva rotulagem, planos de marcação para o acompanhamento de produtos, subprodutos de origem animal e seus derivados, comestíveis ou não, elaborados em estabelecimento registrados no DIPOA. (BRASIL, 1950) 


\section{CAPÍTULO III - QUALIDADE}

Buscando a modernização e racionalização dos sistemas de obtenção, preparação e comercialização de carnes, assim como um melhor entendimento das definições dos cortes de carnes bovina e bubalina estabelecidas na Padronização de Cortes de Carne Bovina, foi instituído o Programa de Distribuição de Carnes Bovina e Bubalina ao Comércio Varejista, previamente embaladas e identificadas. (BRASIL, 1996)

Muitas empresas, em diferentes cadeias produtivas, buscam diversificar a oferta de seus produtos, segmentar o seu mercado e desenvolver novos produtos, de forma a agregar maior valor às matérias-primas de origem agropecuária. Estas tentativas têm por objetivos principais obter a fidelidade dos consumidores a partir do atendimento às suas necessidades e exigências, e aumentar a lucratividades das empresas, conseqüentemente. (PEREZ ET AL, 2002)

Com referência ao mercado interno, é importante ressaltar que os consumidores apreciam o sabor, e, quando consomem em casa, escolhem os cortes para a finalidade a que se destinam e, visivelmente, não julgam a maciez do corte porque encontram estratégias para contornar o problema. Porém, se dispõem de mais dinheiro, ou quando comem em restaurantes, optam por filé mignom, centro de alcatra ou picanha, cortes mais macios, dispensando o contrafilé, de resistência geralmente maior. As peças cárneas dianteiras destinam-se sempre às preparações de carne moída ou de carne cozida na panela, com umidade, e o contrafilé é fatiado em bifes finos, que são martelados, temperados e passados na frigideira quente. Transformar essa mercadoria em produto identificado, seja visando o mercado externo, seja o interno, é um grande desafio para o setor da carne bovina. (FELÍCIO, 1999)

No Brasil de hoje, uma carne que, além da qualidade óbvia, possuísse cor, maciez, suculência e sabor assegurados, e que fosse apresentada nos displays pré-cortada, corretamente embalada, com certificado de origem e indicações de preparo culinário, teria ao mesmo tempo qualidades óbvia e atrativa. Por algum tempo essas características seriam um importante fator de competitividade em relação aos concorrentes que pertencem ao mesmo nicho de mercado. (FELÍCIO, 1999) 
Para transformar uma mercadoria como a carne bovina em um produto que, além de atributos de qualidade óbvia, apresente também qualidade atrativa, é importante compreender adequadamente o que pode e deve ser avaliado em testes organolépticos e medido em testes físicos. (FELÍCIO, 1999)

O rótulo também faz parte dessas características, torna o produto diferente, principalmente na gôndola, onde as embalagens são parecidas. Na interface produto - usuário o reconhecimento do rótulo assegura a fidelidade da compra, além de fornecer ao usuário informações sobre o produto. O poder de comunicação atrativo do rótulo influencia na percepção do consumidor e estimula os aspectos sensoriais. (SCATOLIM, 2008) 


\section{RESULTADOS E DISCUSSÃO}

Foram analisados 99 rótulos de onze marcas diferentes, comercializados em sete redes de supermercados, localizadas no Plano Piloto, em Brasília-DF no período de Dezembro de 2008 a Janeiro de 2009. Foi verificado que os rótulos apresentavam conformidades ou nãoconformidades em relação a 15 itens. Foram obtidos os seguintes resultados:

1) Lista de ingredientes: nenhum rótulo apresentou não-conformidades.

Quanto à lista de ingredientes, 100\% (99) dos rótulos apresentaram conformidades, pois há um único ingrediente: carne bovina resfriada sem osso, e todos os rótulos descreveram no painel principal, ou no secundário, a composição dos produtos. O resultado era esperado, pois a legislação é bastante clara quanto à descrição das peças cárneas bovinas, havendo listas descrevendo as denominações adequadas para cada produto.

2) Conteúdo líquido: nenhum rótulo apresentou o conteúdo líquido. Dentre todos os rótulos, $15,15 \%$ (15) não apresentavam a expressão "Deve ser pesado à vista do consumidor"

Nenhum rótulo identificava o conteúdo líquido. No entanto, a maioria deles, 84,84\% (84) dos rótulos, apresentava a expressão "Deve ser pesado à vista do consumidor". Apesar da presença da expressão, 100\% (99) das peças cárneas, nos estabelecimentos comerciais, já apresentavam a etiqueta com o preço. Já 5,05\% (5) dos rótulos apresentavam a expressão "Venda a peso", não especificando a forma de pesagem. Portanto, apenas 10,1\% (10) dos rótulos possuíam não-conformidades relacionadas à indústria. O restante, 89,89\% (89), relacionava-se com má prática de estabelecimentos comerciais, não respeitando os direitos do consumidor.

A conseqüência para os consumidores das não-conformidades citadas acima é a possibilidade da compra de quantidades inferiores de carne, considerando a quantidade informada na etiqueta do estabelecimento comercial. Uma solução simples para a questão é a exigência, pelo consumidor, de uma nova pesagem da peça cárnea de interesse. Assim, com o tempo, os estabelecimentos comerciais começarão a seguir as indicações dos rótulos para que a peça seja pesada à vista do consumidor. 
A expressão "Deve ser pesado à vista do consumidor" é uma maneira das indústrias produtoras acelerarem o processo de fabricação de carnes, sem que haja necessidade de pesar peça por peça. No entanto, ela permite aos estabelecimentos comerciais práticas ilegais, como a pesagem sem a presença do consumidor. Nesse quesito específico, a fiscalização pode agir proibindo tal prática e orientando os consumidores a exigirem a segunda pesagem da peça.

3) Identificação da origem: nenhum rótulo apresentou não-conformidades.

4) Nome ou razão social e endereço do estabelecimento: 100\% (99) dos rótulos possuíam a informação.

Apesar de todos os rótulos apresentarem informações sobre a origem do produto, nome, razão social, endereço, categoria e CNPJ do estabelecimento produtor, um dos 99 rótulos, 1,01\% (1), apresentava letras em tom amarelo num fundo branco, impossibilitando a leitura. Assim, o estabelecimento responsável pela manufatura de seus rótulos deveria ser aconselhado a mudar a cor da fonte ou a cor de fundo do rótulo, facilitando a leitura pelos consumidores.

A maioria dos estabelecimentos comerciais utiliza cores de fundo e de fontes em contraste, para melhor imagem do rótulo. Entretanto, os responsáveis pela criação dos rótulos deveriam receber treinamentos e orientação, por escrito, em manuais ou fichas técnicas, sobre a necessidade dessa prática, não apenas para a plasticidade do rótulo mas, principalmente, para melhor visualização pelos consumidores.

5) Carimbo oficial da inspeção federal: 29,29\% (29) dos rótulos apresentaram nãoconformidades.

No caso do carimbo oficial da Inspeção Federal, um dos rótulos, 1,01\% (1), apresentou deformações, provavelmente geradas pelo redimensionamento do rótulo, deixando o carimbo ovalado, com as dimensões diferentes das indicadas no R.I.I.S.P.O.A. e com as informações presentes no rótulo embaçadas. Os outros 28 rótulos, 28,28\% (28), apresentaram nãoconformidades com as dimensões, uma vez que as peças apresentavam rótulos dentro do modelo indicado, mas com $4 \mathrm{~cm}$ de diâmetro em peças com menos de um quilograma, 
situação em que o diâmetro do carimbo deveria ser de $2 \mathrm{~cm}$ ou $3 \mathrm{~cm}$, ou mesmo $2 \mathrm{~cm}$ de diâmetro em peças acima de um quilograma.

O R.I.I.S.P.O.A. é claro quanto ao modelo a ser utilizado para peças cárneas resfriadas. Carimbo circular de $2 \mathrm{~cm}$ ou $3 \mathrm{~cm}$, no caso de peças até um quilograma, e carimbo circular de $4 \mathrm{~cm}$ para peças acima de um quilograma. Não obstante, algumas peças se aproximam do valor limite, um quilograma, dificultando a utilização do carimbo. Assim, a empresa deve tentar padronizar suas peças cárneas, através da padronização dos lotes de animais comprados, além de realizar a pesagem das peças, para maior controle de cada lote.

6) Categoria do estabelecimento: 100\% (99) dos rótulos possuíam a informação.

7) CNPJ: 100\% (99) dos rótulos possuíam a informação.

8) Conservação do produto: 12,12\% (12) dos rótulos apresentaram não-conformidades.

Quanto à conservação do produto, $12,12 \%$ (12) dos rótulos não apresentavam a faixa de temperatura para a preservação da carne. Por serem carnes resfriadas embaladas a vácuo, deveria haver uma indicação para que se mantivessem as peças em uma temperatura variando entre $0^{\circ} \mathrm{C}$ e $7^{\circ} \mathrm{C}$, podendo a faixa ser menor, de acordo com o tempo indicado como prazo de validade do produto. Já aqueles que apresentavam a temperatura de preservação não indicavam as ações a serem tomadas após a abertura da embalagem.

A indicação da faixa de temperatura de conservação é informação obrigatória de rótulos de carnes embaladas a vácuo. Porém, não há informações relativas à abertura da embalagem, o que pode levar a uma má interpretação pelos consumidores. As empresas produtoras, além de indicar a faixa de conservação, deveriam apresentar informações sobre os procedimentos a serem tomados após a abertura da embalagem, como é o caso da expressão "Após aberto, consumir em dias", encontrada em diversos produtos.

Em relação à saúde do consumidor, as não-conformidades intrínsecas à conservação do produto são críticas. Peças cárneas conservadas inadequadamente apresentam maior taxa de deterioração e, consequentemente, maior probabilidade de crescimento microbiano, além da perda das características organolépticas naturais da carne. 
9) Marca comercial do produto: 28,28\% (28) dos rótulos apresentaram não-conformidades.

Dos 99 rótulos analisados, 19,19\% (19) apresentaram nomenclatura estrangeira na marca, sem tradução em vernáculo. Além disso, a expressão presente na marca de 8,08\% (8) dos rótulos indicava uma característica não comprovada do produto, o que é caracterizado como nãoconformidade. Uma marca específica, presente em 9,09\% (9) dos rótulos analisados, apresentava faixas verdes e amarelas no rótulo, o que poderia ser relacionado à Bandeira Nacional. Como são proibidas alusões a este símbolo, de acordo com o artigo 800 do R.I.I.S.P.O.A., caracterizou-se não-conformidade.

A utilização de nomenclatura estrangeira é prática comum. Considerando que a maioria da população tem pouco ou nenhum acesso ao estudo de outros idiomas, faz-se necessário um maior rigor nesse quesito, orientando as indústrias a não utilizarem tais expressões, ou apresentarem traduções, no mesmo painel.

10) Identificação do lote: 3,03\% (3) dos rótulos apresentaram não-conformidades.

A identificação do lote não estava presente em 3,03\% (3) dos rótulos. No entanto, 26,26\% (26) dos rótulos apresentavam como identificação do lote a própria data de fabricação. Como diversos produtos analisados apresentavam a mesma data de fabricação, esse tipo de prática pode levar a uma interpretação equivocada pelos consumidores, caracterizando falsa impressão, prática proibida pelo D.I.P.O.A..

Utilizada em diversos países, a rastreabilidade possibilita o controle das etapas da cadeia de suprimentos, fornecendo instrumentos essenciais para análise e gestão de riscos. A rastreabilidade já é adotada, em alguns países, como prática obrigatória para reconstituição da origem, embalagem, transporte e armazenagem de produtos. Controlando de maneira mais eficiente os riscos, a empresa pode oferecer mais segurança e confiabilidade ao consumidor. Por isso, a questão da segurança do alimento é tão importante.

É desejável que todo sistema de identificação seja prático e simples, seja baseado em padrões internacionais e apresente um custo adequado. Dessa forma, os diferentes processos de identificação do lote encontrados demonstram a inadequação desse processo realizado pelos setores da produção de carne, sendo necessário um maior investimento na tecnificação e 
padronização do SISBOV, Sistema Brasileiro de Identificação e Certificação de Origem Bovina e Bubalina.

11) Data de fabricação: 0\% (0) dos rótulos apresentou não-conformidades.

12) Prazo de validade: $0 \%$ (0) dos rótulos apresentou não-conformidades.

Todos os rótulos apresentavam data de fabricação, assim como o prazo de validade, de acordo com o artigo 797 do R.I.I.S.P.O.A., detalhando dia, mês e ano. No entanto, os prazos de validade variaram entre dois e três meses, de acordo com a marca, não importando o corte específico. Como existem cortes com variações significativas de proteínas e lipídeos, o prazo de validade deveria ser calculado para cada corte.

Por exemplo, o cupim, a costela e a fraldinha, cortes mais gordurosos, possuem o mesmo prazo de validade que o filé mignon, que possui um baixo teor de gordura e um alto teor protéico. Uma vez que alimentos mais gordurosos deterioram-se mais rapidamente, o prazo de validade de peças como o cupim deveria ser menor. Já que os valores variaram aleatoriamente de dois a três meses, as indústrias produtoras poderiam estabelecer o prazo de dois meses como validade para as peças mais gordurosas e três meses para as peças menos gordurosas, até que testes laboratoriais fossem realizados para determinar o real prazo de cada peça específica.

Outro caso é o conteúdo intersticial extravasado das peças, ou seja, os líquidos que permanecem na embalagem. A presença do líquido, caso haja contaminação por microorganismos anaeróbios, pode levar a uma deterioração acelerada da peça, diminuindo sua vida de prateleira. Nesse caso, o ideal seria embalar a peça após a verificação da presença de excesso de umidade, na temperatura adequada de preservação e enfatizar aos pontos de venda a necessidade da permanência na faixa de temperatura estabelecida, além de realização de campanhas de educação para os consumidores.

13) Composição do produto: $18,18 \%$ (18) dos rótulos apresentaram não-conformidades.

A composição do produto foi um quesito que apresentou não-conformidades em 18,18\% (18) dos rótulos, todos relacionados à nomenclatura do corte. Duas marcas apresentaram peças 
com as nomenclaturas "Orgânico" e "Grill" na nomenclatura oficial, termos não permitidos pela legislação vigente. Os atributos "Orgânico" e "Grill” poderiam estar presentes no rótulo, porém em outra região que não na denominação da peça cárnea.

14) Indicação da expressão "Registro no Ministério da Agricultura SIF/DIPOA sob n ${ }^{\circ}$--------“: $1,01 \%$ (1) dos rótulos apresentaram não-conformidades.

Um único rótulo apresentou duas vezes a expressão "Registro no Ministério da Agricultura SIF/DIPOA sob $n^{0}$----/----“ em seu painel secundário, um possível erro de impressão. No caso, uma não-conformidade menos grave que a não ocorrência da expressão, não sendo significativa.

15) Indicação da expressão "Indústria Brasileira": 0\% (0) dos rótulos apresentou nãoconformidades.

A expressão "Indústria Brasileira" estava presente em 100\% (99) dos rótulos, em seus painéis secundários ou principais. No entanto, 35,35\% (35) dos rótulos apresentaram a expressão em caixa alta, o restante, 64,64\% (64), não. Faz-se necessária uma padronização no uso dessa expressão, para facilitar a análise de rotulagens por fiscais federais agropecuários e a própria elaboração dessas rotulagens pelas indústrias.

Além das informações obrigatórias determinadas pelo R.I.I.S.P.O.A., outras informações foram identificadas no estudo, como a apresentação dos rótulos, a expressão "Contém Glúten" ou "Não Contém Glúten", de acordo com a Lei No 10674, de 16 de maio de 2003, a posição da etiqueta de preços dos supermercados em relação aos rótulos, além de informações diferenciadas de cada rótulo.

Quanto à apresentação, 21,21\% (21) dos rótulos apresentaram não-conformidades, estando amassados ou dobrados. Duas razões principais para esta não-conformidade são o modo de embalagem, já que no processo de embalagem a vácuo há uma diminuição do volume da embalagem plástica, o que pode amassar o rótulo, e a utilização de filmes plásticos envolvendo as embalagens originais, prática normalmente feita por supermercados, o que pode amassar e dobrar os rótulos, ou mesmo escondê-los. Uma possível solução seria centralizar o rótulo, já que as regiões menos afetadas da embalagem termoretrátil são as 
regiões centrais. Quanto aos filmes plásticos utilizados por supermercados, deve-se enfatizar a não necessidade de utilização dos mesmos, já que as embalagens de peças cárneas são resistentes o suficiente.

A grande maioria dos rótulos, 95,95\% (95) deles, apresentava a expressão "Não Contém Glúten" no painel secundário, como indicado pela Lei 10674, de 2003. Um dos rótulos apresentou a expressão em tamanho que dificulta a leitura pelos consumidores. Já outro rótulo apresentou sobreposição de informações impressas, incluindo a expressão.

As etiquetas dos supermercados foram responsáveis pela sobreposição de sete rótulos. Por ter que etiquetar centenas de produtos em pouco tempo, funcionários de supermercados muitas vezes ignoram a importância das informações presentes nos rótulos, escondendo-as, o que pode ser facilmente corrigido com treinamentos internos nos supermercados.

Uma das marcas analisadas, além de indicar a temperatura ideal para preservação da peça cárnea, indicou também o local para que ocorra essa preservação, no caso, um refrigerador. Outra marca enfatizou uma das características de seu produto, o fato de ser orgânico. Uma terceira marca indicava que seu produto apresentava maior qualidade por serem carnes já limpas. Essas características sugeridas pelas marcas podem agregar valor ao produto, fazendo com que o mesmo seja valorizado por consumidores, além de serem alternativas para diversos setores do comércio alimentar.

Todos os rótulos apresentavam telefones para contato com o SAC, Serviço de Atendimento ao Consumidor, importante ferramenta para a garantia dos direitos do consumidor, assegurados pela Lei $N^{\circ}$ 8078, de 11 de setembro de 1990. Além dessa informação, doze rótulos, de uma mesma rede de matadouros-frigoríficos, apresentaram email para contato, ampliando as formas de comunicação empresa-cliente.

Os resultados podem ser melhor visualizados na tabela a seguir:

Tabela 1: Quantidade e porcentagem total de conformidades e não-conformidades encontradas em rótulos de peças cárneas embaladas a vácuo.

\begin{tabular}{|l|l|l|}
\hline Itens analisados & Conformes & Não conformes \\
\hline Lista de ingredientes & $99(100 \%)$ & $0(0 \%)$ \\
\hline
\end{tabular}




\begin{tabular}{|l|l|l|}
\hline Conteúdo líquido & $84(84,84 \%)$ & $15(15,15 \%)$ \\
\hline Identificação da origem & $99(100 \%)$ & $0(0 \%)$ \\
\hline Nome ou razão social e endereço do estabelecimento & $99(100 \%)$ & $0(0 \%)$ \\
\hline Carimbo oficial da Inspeção Federal & $70(70,7 \%)$ & $29(29,29 \%)$ \\
\hline Categoria do estabelecimento & $99(100 \%)$ & $0(0 \%)$ \\
\hline CNPJ & $99(100 \%)$ & $0(0 \%)$ \\
\hline Conservação do produto & $87(87,87 \%)$ & $12(12,12 \%)$ \\
\hline Marca comercial do produto & $71(71,71 \%)$ & $28(28,28 \%)$ \\
\hline Identificação do lote & $96(96,96 \%)$ & $3(3,03 \%)$ \\
\hline Data de fabricação & $99(100 \%)$ & $0(0 \%)$ \\
\hline Prazo de validade & $99(100 \%)$ & $0(0 \%)$ \\
\hline Composição do produto & $81(81,81 \%)$ & $18(18,18 \%)$ \\
\hline Indicação da expressão de registro & $98(98,98 \%)$ & $1(1,01 \%)$ \\
\hline "Indústria Brasileira" & $99(100 \%)$ & $0(0 \%)$ \\
\hline
\end{tabular}

Por conseguinte, é necessária a fiscalização da rotulagem dos produtos destinados ao consumo, não apenas por fiscais federais agropecuários, mas também pelos próprios consumidores, para que se mantenha a conservação de seus direitos e a exigência pelos padrões de qualidade no mercado interno.

Dessa forma, verifica-se a ocorrência maior de algumas não-conformidades em relação a informações obrigatórias, como pode ser verificado no gráfico a seguir.

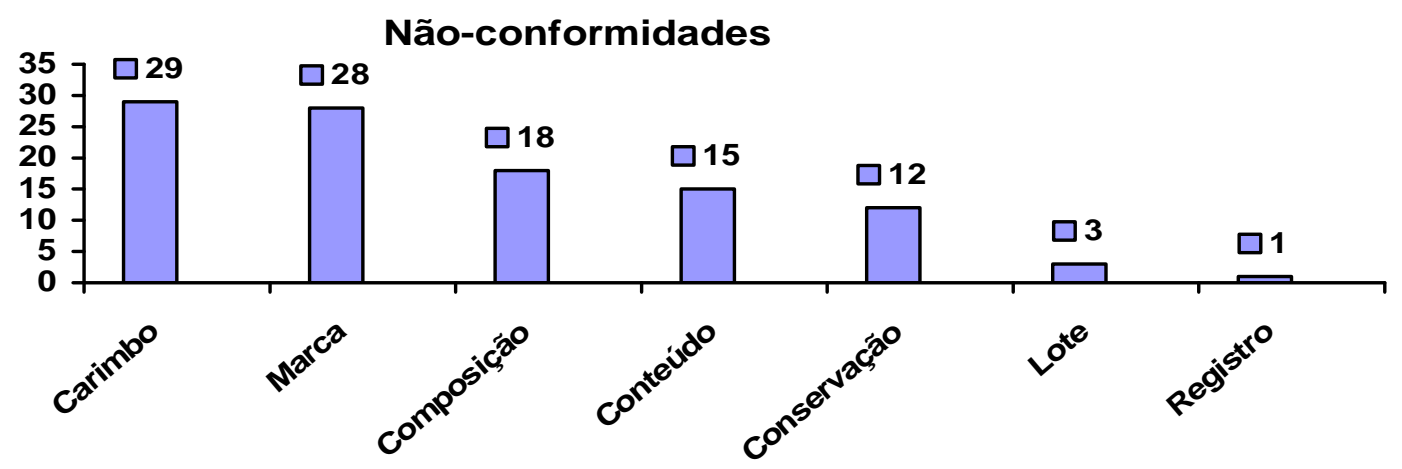

Figura 1: gráfico com freqüências das não-conformidades em rótulos de peças cárneas. 


\section{CONCLUSÃO}

A análise de rotulagem é um processo que começa nos estabelecimentos produtores, por meio do responsável técnico. Em seguida, os rótulos são analisados pelo Ministério da Agricultura, Pecuária e Abastecimento, pelos fiscais federais agropecuários, com a participação da Agência Nacional de Vigilância Sanitária e as vigilâncias sanitárias estaduais, até chegarem aos estabelecimentos comerciais.

Apesar do longo e minucioso processo de análise, várias não-conformidades ainda são verificadas em rótulos de carnes. Esse estudo demonstra a importância, que deve ser ressaltada, à fiscalização dos rótulos dos alimentos in natura, por parte de todos os profissionais atuantes. Desta forma, será garantida a segurança dos consumidores e a certeza das informações apresentadas nos rótulos.

Também foi demonstrada a grande quantidade de não-conformidades relacionadas ao carimbo oficial da Inspeção Federal e à marca comercial do produto, estando presentes, cada uma das não-conformidades, em quase $30 \%$ dos rótulos. De posse dessa informação, as indústrias produtoras poderão facilmente efetuar as medidas corretivas necessárias à padronização, nos termos legais, de seus rótulos, através da utilização do modelo correto do carimbo e da retirada de informações que possam conduzir o consumidor ao engano, como palavras estrangeiras sem tradução em vernáculo.

A conservação do produto, informação que apresentou não-conformidades em $12,12 \%$ dos rótulos, é a característica mais crítica em relação à saúde do consumidor. Falhas no armazenamento e conservação de peças cárneas podem levar a diversas patologias sendo necessária, portanto, maior fiscalização e maior controle na forma como essa informação é transmitida.

Portanto, comprova-se a necessidade de um trabalho mais pormenorizado na elaboração e análise de rótulos, com o foco não apenas na tabela nutricional, mas nas outras informações obrigatórias. Também se faz necessária a realização de manuais e treinamentos, ministrados por fiscais federais agropecuários, a respeito da elaboração de rótulos pelos estabelecimentos produtores. 


\section{REFERÊNCIAS BIBLIOGRÁFICAS}

Aiello, SE. Manual Merck de Veterinária. $8^{\text {a }}$ Ed. São Paulo. Roca. 2001. 1009.

American Dietetic Association. Position of the American Dietetic Association: nutrition and health information on food labels. J Am Diet Assoc 1990.

Bick, LFA. A legislação brasileira sobre embalagem e rotulagem de alimentos. In: IV Congresso Brasileiro de Embalagem. São Paulo, 1986. São Paulo, Associação Brasileira de Embalagem, 1986. P.151.

Brasil. Cadeia produtiva da carne bovina / Ministério da Agricultura, Pecuária e Abastecimento, Secretaria de Política Agrícola, Instituto Interamericano de Cooperação para a Agricultura ; Antônio Márcio Buainain e Mário Otávio Batalha (coordenadores). - Brasília : IICA : MAPA/SPA, 2007.

Brasil. Circular N $\mathrm{N}^{\circ}$ 53, DE 19 DE MAIO DE 1988. Critérios adotados para obtenção do produto "Carne Resfriada" (ou congelada) de Bovinos sem osso (corte maturado). Ministério da Agricultura, Pecuária e Abastecimento. Secretaria de Defesa Agropecuária. Divisão de Inspeção de Produtos de Origem Animal. 2p. 1988.

Brasil. Decreto-Lei n.986, de 21 de outubro de 1969. Dispõe sobre normas básicas sobre alimentos dos Ministérios da Marinha de Guerra, do Exército e da Aeronáutica Militar. Diário Oficial da União. 196921 out; Seção 1.

Brasil. Decreto N $N^{\circ}$ 25386, DE 19 DE AGOSTO DE 1948. Aprova o novo regimento do Departamento Nacional da Produção Animal, do Ministério da Agricultura. Diário Oficial da União de 08/09/1948, Seção 1, Página 12973.

Brasil. Decreto No 30691, DE 29 DE MARÇO DE 1952. Aprova o novo Regulamento da Inspeção Industrial e Sanitária de Produtos de Origem Animal. Diário Oficial da União de 07/07/1952, Seção 1, Página 10785.

Brasil. Instrução Normativa $N^{\circ}$ 5, DE 31 DE DEZEMBRO DE 1998. Estabelece a data de 04 de janeiro de 2000, como limite máximo, para a adoção do Regulamento Técnico para Rotulagem de Alimentos Embalados. Diário Oficial da União de 05/01/1999, Seção 1 , Página 11.

Brasil. Instrução Normativa $\mathrm{N}^{\circ}$ 22, DE 24 DE NOVEMBRO DE 2005. Aprova o Regulamento Técnico para Rotulagem de Produto de Origem Animal embalado. Diário Oficial da União de 25/11/2005, Seção 1 , Página 15.

Brasil. Lei No 1283, DE 18 DE DEZEMBRO DE 1950. Dispõe sôbre a inspeção industrial e sanitária dos produtos de origem animal. Diário Oficial da União de 19/12/1950 , Seção 1 , Página 18161.

Brasil, Lei $\mathrm{N}^{\circ}$ 8078, DE 11 DE SETEMBRO DE 1990. Dispõe sobre a proteção do consumidor e dá outras providências. Diário Oficial da União de 12/09/1990, suplemento. 
Brasil, Lei No 10764, DE 16 DE MAIO DE 2003. Obriga a que os produtos alimentícios comercializados informem sobre a presença de glúten, como medida preventiva e de controle da doença celíaca. Diário Oficial da União de 19/05/2003, Seção 1.

Brasil. Portaria $N^{\circ} 75$, DE 20 DE FEVEREIRO DE 1975. Regimentos Internos do Departamento Nacional de Inspeção de Produtos de Origem Animal. Diário Oficial da União de 05/03/1975, Seção 1, Página 2716.

Brasil. Lei No 1283, DE 18 DE DEZEMBRO DE 1950. Dispõe sobre a inspeção industrial e sanitária dos produtos de origem animal. Diário Oficial da União de 19/12/1950 , Seção 1 , Página 18161.

Brasil. Portaria Nº 89, DE 15 DE JULHO DE 1996. Institui o Programa de Distribuição de Carnes Bovina e Bubalina ao Comércio Varejista, previamente embaladas e identificadas. Diário Oficial da União de 07/08/1996, Seção 1 , Página 14893.

Brasil. Rotulagem nutricional obrigatória: manual de orientação às indústrias de Alimentos - $2^{\mathbf{0}}$ Versão / Agência Nacional de Vigilância Sanitária - Universidade de Brasília. 44p. Brasília, 2005.

Celeste, RK. Análise comparativa da legislação sobre rótulo alimentício do Brasil, Mercosul, Reino Unido e União Européia. Rev Saúde Pública 2001; 35(3):217-23.

De Quadros, CWB. O uso da embalagem de carne pelo frigorífico: mudanças na cadeia produtiva da carne bovina na perspectiva do frigorífico e do produtor rural. $41 \mathrm{p}$. Porto Alegre. 2001.

Dibb, S. What the label doesn't tell you. London: Thorson; 1997.

Felício, PE. Avaliação da Qualidade da Carne Bovina. In: Simpósio sobre Produção Intensiva de Gado de Corte, 1998, Campinas. Anais. São Paulo: Colégio Brasileiro de Nutrição Animal (CBNA), 1998, p.92-99.

Felício, PE. Qualidade da Carne Bovina: Características Físicas e Organolépticas. Faculdade de Engenharia de Alimentos da Unicamp, Campinas SP . 11p. 1999.

Felício, PE. Uma Análise Crítica, Porém Otimista, da Carne Bovina do Brasil Central Pecuário. I Encontro Nacional do Boi Verde. 9p. Uberlândia, 1999.

Ferreira, $\mathrm{AB}$, Lanfer-Marquez $\mathrm{UM}$; Legislação brasileira referente à rotulagem nutricional de alimentos. Rev. Nutr., Campinas, 20(1):83-93, jan./fev., 2007

Hickman, BW; Gates, GE; Dowdy, RP. Nutrition claims in advertisement: a study of four women's magazines. $J$ Nutr Educ 1993;25:227-35.

Hyman, DJ; Simons-Morton, DG; Ho, K; Dunn, JK; Rubovits, DS. Cholesterol related knowledge, attitudes and behaviour in a low-income urban patient population. $A m J$ Prev Med 1993;9:282-9. 
Monteiro, RA; Coutinho, JG; Recine, E. Consulta aos rótulos de alimentos e bebidas por frequientadores de supermercados em Brasília, Brasil. Rev Panam Salud Publica. $2005 ; 18(3): 172-77$.

Perez, R; Rios, JAD; Bandeira, ML. Agregação de Valor: Caso da Cadeia de Carne Bovina. XXII Encontro Nacional de Engenharia de Produção. 8p. Curitiba, 2002.

Santos, RC, Castro, VMF. Uma proposição sistêmica para o desenvolvimento de embalagens. RAE - Revista de Administração de Empresas, Fundação Getúlio Vargas, v. 38, $n^{\circ} 2$ : 26-35, Abr./Jun., 1998.

Scatolim, RL. A Importância do Rótulo na Comunicação Visual da Embalagem: Uma Análise Sinestésica do Produto. 10p. Unesp, FAAC, Bauru, SP, 2008.

Souza, R. Rotulagem Nutricional Continua Gerando Dúvidas. CrN Notícias. Edição 73, página 6. São Paulo, 2005. Disponível no site <http://www.crn3.org.br> Acessado em 05/10/2008.

World Health Organization. Ottawa Charter for health promotion. International Conference on Health Promotion; 1986 nov 17-21; Ontario, Canada.

Yetley EA, Rader JI. The challenge of regulating health claims and food fortification. $J$ Nutr 1996. 


\section{ANEXOS}

1. Formulário de informações obrigatórias em rótulos de carnes in natura embaladas a vácuo.

\begin{tabular}{|l|l|l|}
\hline INFORMAÇÃO & CONFORME & NÃO CONFORME \\
\hline Lista de ingredientes & & \\
\hline Conteúdo líquido & & \\
\hline Origem & & \\
\hline Nome e endereço do estab. & & \\
\hline Carimbo oficial do SIF & & \\
\hline Categoria do estabelecimento & & \\
\hline CNPJ & & \\
\hline Conservação do produto & & \\
\hline Marca comercial do produto & & \\
\hline Identificação do lote & & \\
\hline Data de fabricação & & \\
\hline Prazo de validade & & \\
\hline “Indústria Brasileira” & & \\
\hline Expressão de registro & & \\
\hline
\end{tabular}

2. Modelo de carimbo utilizado para carnes in natura.

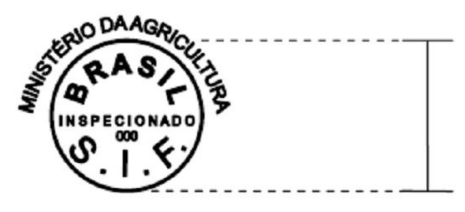

$$
2 \mathrm{~cm}
$$
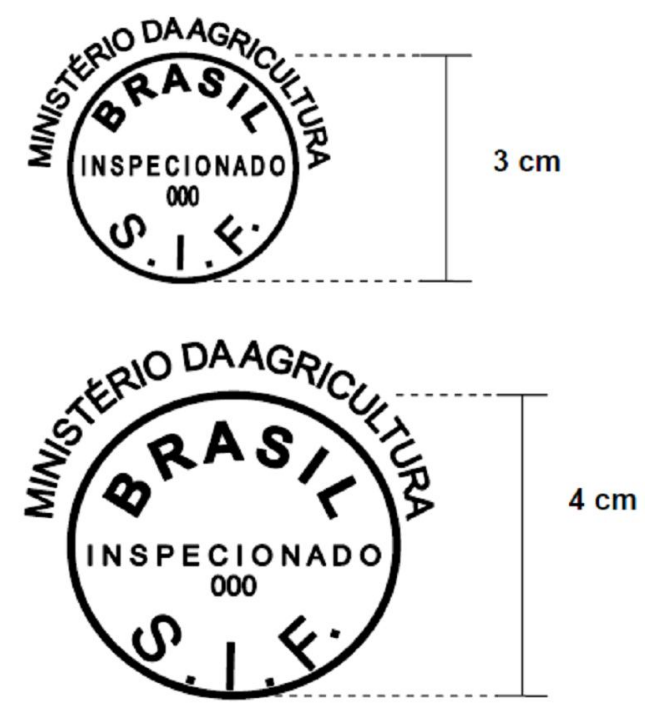